\title{
Effect of evodiamine on the proliferation and apoptosis of A549 human lung cancer cells
}

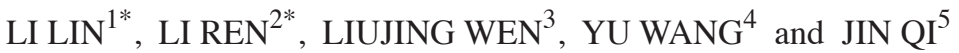 \\ ${ }^{1}$ Department of Thoracic Oncology, Tianjin Medical University Cancer Institute and Hospital, National Clinical Research \\ Center for Cancer, Lung Cancer Diagnosis and Treatment Center, Key Laboratory of Cancer Prevention and Therapy; \\ Departments of ${ }^{2}$ Clinical Laboratory and ${ }^{3}$ Pharmacy, Tianjin Medical University Cancer Institute and Hospital, \\ National Clinical Research Center for Cancer, Key Laboratory of Cancer Prevention and Therapy, \\ Tianjin's Clinical Research Center for Cancer, Tianjin 300060; ${ }^{4}$ Department of Radiology, \\ Tianjin State Key Laboratory of Modern Chinese Medicine, Tianjin University of Traditional Chinese Medicine, \\ Tianjin 300193; ${ }^{5}$ Department of Radiology, Tianjin Medical University Cancer Institute and Hospital, \\ National Clinical Research Center for Cancer, Key Laboratory of Cancer Prevention and Therapy, \\ Tianjin's Clinical Research Center for Cancer, Tianjin 300060, P.R. China
}

Received July 4, 2015; Accepted June 24, 2016

DOI: $10.3892 / \mathrm{mmr} .2016 .5575$

\begin{abstract}
Evodia rutaecarpa is a plant, which has antitumor activity. Evodiamine is an alkaloid with antitumor activity present in E.rutaecarpa and has potential to be developed into a therapeutic antitumor agent. The present study investigated the effect of evodiamine on the proliferation of A549 human lung cancer cells and the mechanism underlying these effects. The results indicated that evodiamine significantly inhibited proliferation, induced apoptosis and the expression of reactive oxygen species, arrested the cell cycle, regulated the expression of Survivin, Bcl-2 and Cyclin B1, regulated the activity of caspase-3/8 and glutathione in tumor cells, and decreased the activity of $\mathrm{AKT} /$ nuclear factor $-\kappa \mathrm{B}(\mathrm{NF}-\kappa \mathrm{B})$ and Sonic hedgehog/GLI family zinc finger 1 (SHH/GLI1) signaling pathways in A549 cells. In conclusion, the evodiamine-induced inhibition of the proliferation of A549 lung cancer cells may be attributable to its ability to promote oxidative injury in the cells, induce apoptosis, arrest the cell cycle and regulate the AKT/NF- $\kappa$ B and SHH/GLI1 signaling pathways, subsequently controlling the expression of tumor-associated genes.
\end{abstract}

Correspondence to: Dr Li Lin, Department of Thoracic Oncology, Tianjin Medical University Cancer Institute and Hospital, National Clinical Research Center for Cancer, Tianjin Lung Cancer Center, Key Laboratory of Cancer Prevention and Therapy, Huanhu Western Road, Hexi, Tianjin 300060, P.R. China

E-mail: linli76@163.com

${ }^{*}$ Contributed equally

Key words: evodiamine, lung cancer, apoptosis, oxidative damage

\section{Introduction}

Lung cancer is a common type of malignancy, with the majority of individuals presenting with advanced disease (1). However, the tumor treatment is a complex process. In the past few decades, the survival of patients with lung cancer has improved as surgical techniques have become more aggressive to achieve optimal cytoreduction and platinum-based treatment has been introduced (2). Although $80 \%$ of cancers initially respond to chemotherapy, the majority ultimately reoccur with $<15 \%$ of patients remaining in remission (3). Therefore, there is an urgent requirement for novel drugs for the prevention and treatment of lung cancer (4). Thus, research has focused on identifying novel effective antitumor drugs and determining their mechanisms of action (5). Previous studies have indicated that the consumption of Evodia rutaecarpa may reduce the incidence of cancer. Evodiamine is active ingredient that exerts antitumor activity. Evodiamine, as a naturally occurring alkaloid, is widely present in E. rutaecarpa (6-8). Despite its fairly high antitumor activity, the effects of evodiamine on lung cancer have not been fully elucidated to the best of our knowledge. The inhibitory effect of evodiamine and its mechanism of action on the A549 human lung cancer cell line was investigated by observing the effects of evodiamine on cell proliferation, apoptosis, the cell cycle, reactive oxygen species (ROS) production and the relevant signal transduction pathways.

\section{Materials and methods}

Cell culture. A549 cells (American Type Culture Collection, Manassas, VA, USA) were maintained in 90\% Dulbecco's modified Eagle's medium (Corning, Manassas, VA, USA) containing $10 \%$ fetal bovine serum and cultured in an incubator at $37^{\circ} \mathrm{C}$ and $5 \% \mathrm{CO}_{2}$ with saturated humidity conditions. The cells were digested with $0.25 \%$ trypsin-EDTA for passaging. All experiments used cells in the logarithmic growth phase. 
Determination of the effect of evodiamine on tumor cell proliferation with an MTS assay. Cells were seeded at $5 \times 10^{3}$ cells/well in 96-well plates. Evodiamine (Sigma-Aldrich, St. Louis, MO, USA) was added to obtain final concentrations of $0,2.5,5,10$, 25,50 and $100 \mu \mathrm{M}$. The plates were then placed in an incubator for routine culture under $37^{\circ} \mathrm{C}$ and $5 \% \mathrm{CO}_{2}$ conditions. Samples were collected at $72 \mathrm{~h}$ to determine the optical density (OD). Inhibition rate $=(1-$ OD of experimental group / OD of control group) $\mathrm{x}$ 100. The fitting curve was plotted using logarithmic concentration of evodiamine as abscissa and inhibition rate as ordinate. The compound concentration corresponding to $50 \%$ inhibition rate was the $\mathrm{IC}_{50}$. Phosphate-buffered saline (PBS) was used as the negative control.

Determination of apoptosis, cell cycle and ROS expression with flow cytometry. Tumor cells in the logarithmic growth phase were seeded in 6-well plates at a density of $5 \times 10^{5}$ and cultured for $24 \mathrm{~h}$. PBS or 1 or $2.5 \mu \mathrm{M}$ evodiamine were separately added to the test wells and cells were cultured for $24 \mathrm{~h}$. The cells were harvested and incubated with $10 \mu \mathrm{l}$ Annexin V-fluorescein isothiocyanate/propidium iodide (PI) away from light for 15 min prior to flow cytometry using a FACSAria flow cytometer (BD Biosciences, Franklin Lakes, NJ, USA) in order to determine the effect of evodiamine on the apoptosis of tumor cells. Next, PBS or 1 and $2.5 \mu \mathrm{M}$ evodiamine were added to the test wells and cells were cultured for $24 \mathrm{~h}$. The cells were harvested and incubated with $25 \mu \mathrm{l}$ PI away from light for $15 \mathrm{~min}$. Flow cytometry was used to determine the effect of evodiamine on the cell cycle of tumor cells. PBS or 1 or $2.5 \mu \mathrm{M}$ evodiamine were added to the test wells to continue the culture for $24 \mathrm{~h}$. The cells were harvested and incubated with $20 \mu \mathrm{l}$ dihydroethidium away from light for $15 \mathrm{~min}$ prior to the use of flow cytometry to determine the effect of evodiamine on ROS expression in tumor cells. N-acetyl-L-cysteine (NAC; 20 mM; Sigma-Aldrich), which protects against oxidation, was added to determine whether evodiamine affects oxidative stress. DIVA 6.1.3 software (BD Biosciences) was used to analyze flow cytometry results.

Determination of caspase-3/8 activity in tumor cells with a microplate reader. Tumor cells in logarithmic growth phase were seeded in 6-well plates at a density of $5 \times 10^{5}$ and cultured for $24 \mathrm{~h}$. PBS or 1 or $2.5 \mu \mathrm{M}$ evodiamine were separately added to the test wells and were cultured for $24 \mathrm{~h}$. The cells were harvested and lysed to extract the proteins by protein extraction kit (Beyotime Institute of Biotechnology, Shanghai, China). The protein content in cell lysate was determined with a bicinchoninic acid assay. Then, caspase- 3 and caspase- 8 activity test reagent was added in accordance with the kit (Promega Corporation, Madison, WI, USA) instructions to incubate at room temperature for $30 \mathrm{~min}$. The caspase-3/8 activity in these cells was determined with a microplate reader by luminescent signal.

Determination of $m R N A$ expression of proliferation-associated genes in tumor cells with reverse transcription-quantitative polymerase chain reaction $(R T-q P C R)$. Tumor cells $\left(5 \times 10^{5}\right)$ in logarithmic growth phase were seeded in 6-well plates and cultured for $24 \mathrm{~h}$. PBS or 1 or $2.5 \mu \mathrm{M}$ evodiamine were separately added to the test wells and cultured for $24 \mathrm{~h}$. Once the

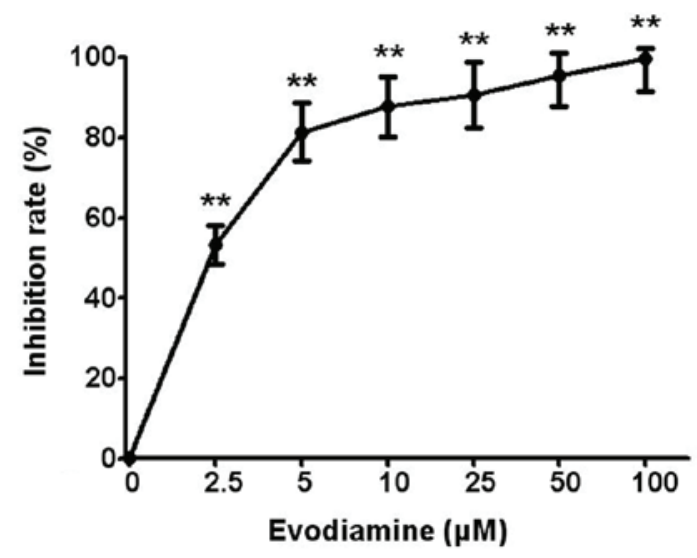

Figure 1. Inhibitory effect of evodiamine on the proliferation of A549 cells. A549 cells were treated with evodiamine at different concentrations $(0,2.5,5,10,25,50$ and $100 \mu \mathrm{M})$ for $72 \mathrm{~h}$. Proliferation of tumor cells was measured by an MTS assay. ${ }^{* *} \mathrm{P}<0.01$ vs. control.

total RNA was extracted with TRIzol (Invitrogen, Thermo Fisher Scientific, Inc.) from each group, the real-time PCR kit [Takara Biotechnology (Dalian) Co., Ltd., Dalian, China] was used for reverse transcription to obtain the cDNA $(2 \mu \mathrm{l})$. The cDNA was then amplified by specific primers using the ABI7500 system (Applied Biosystems, Waltham, MA, USA). The primer pairs were as follows: Survivin, forward (F) 5'-CGAGGCTGG CTTCATCCACT-3' and reverse (R) 5'-ACGGCGCACTTT CTTCGCA-3'; Bcl-2, F 5'-GGCTGGGATGCCTTTGTG-3' and R 5'-GCCAGGAGAAATCAAACAGAGG-3'; cyclin B1, F 5'-TCTGGATAATGGTGAATGGACA-3' and R 5'-CGATGT GGCATACTTGTTCTTG-3'; Sonic hedgehog (SHH), F 5'-GTG GCCGAGAAGACCCTA-3' and R 5'-CAAAGCGTTCAACTT GTCCTTA-3'; GLI family zinc finger 1 (GLI1), F 5'-AGCGTG AGCCTGAATCTGTG-3' and R 5'-CAGCATGTACTGGGC TTTGAA-3'; $\beta$-actin, F 5'-CTCGCTGTCCACCTTCCA-3' and R 5'-GCTGTCACCTTCACCGTTC-3'. The PCR conditions were $95^{\circ} \mathrm{C}$ for $5 \mathrm{~min}$, and then 40 cycles at $95^{\circ} \mathrm{C}$ for $35 \mathrm{sec}, 60^{\circ} \mathrm{C}$ for $35 \mathrm{sec}$, and $72^{\circ} \mathrm{C}$ for $65 \mathrm{sec}$, and extension step at $72^{\circ} \mathrm{C}$ for $10 \mathrm{~min}$. The $2^{-\Delta \Delta \mathrm{Cq}}$ method was used for relative quantifications (9).

Determination of protein expression of proliferation-associated genes in tumor cells using western blotting. Tumor cells in logarithmic growth phase $\left(5 \times 10^{5}\right)$ were seeded in 6-well plates and cultured for $24 \mathrm{~h}$. PBS or 1 or $2.5 \mu \mathrm{M}$ evodiamine were separately added to the test wells and cultured for $24 \mathrm{~h}$. The cells were harvested and lysed to extract the proteins by protein extraction kit (Beyotime Institute of Biotechnology). Next, $100 \mu$ l total protein was applied in $12 \%$ sodium dodecyl sulfate polyacrylamide gel electrophoresis for separation by electrophoresis. The separated proteins were transferred onto a polyvinylidene difluoride membrane. The membrane was blocked in blocking solution containing 5\% skimmed milk powder for $2 \mathrm{~h}$. The membranes were then incubated with monoclonal antibodies against Survivin (cat. no. sc-8807; 1:1,500); Bcl-2 (cat. no. sc-492; 1:1,500); cyclin B1, (cat. no. sc-752; 1:1,500); AKT (cat. no. sc-5298; 1:1,000); p-AKT (cat. no. sc-135650; 1:1,000); nuclear factor (NF)- $\mathrm{B}$ p65 (cat. no. sc-372; 1:1,000); p-p65, (cat. 
A

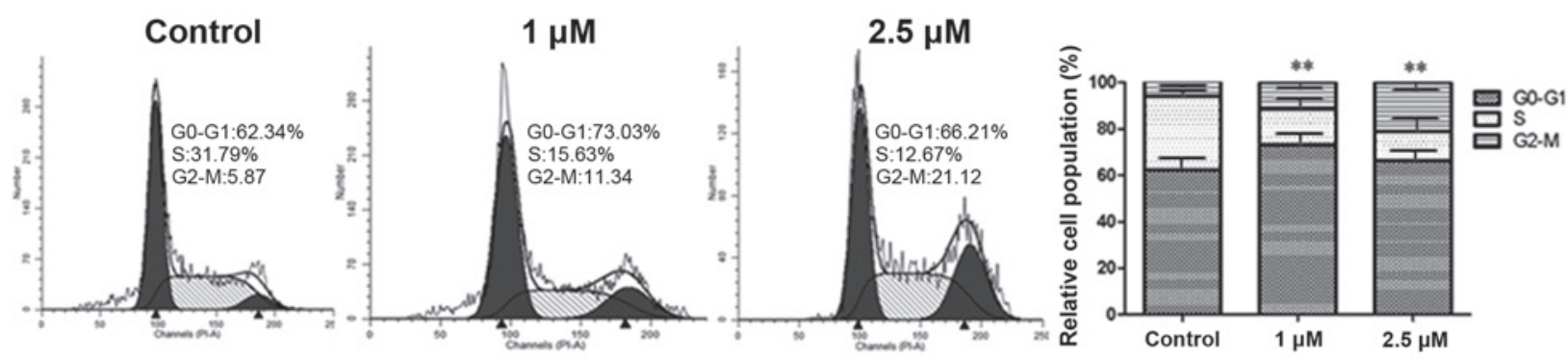

B

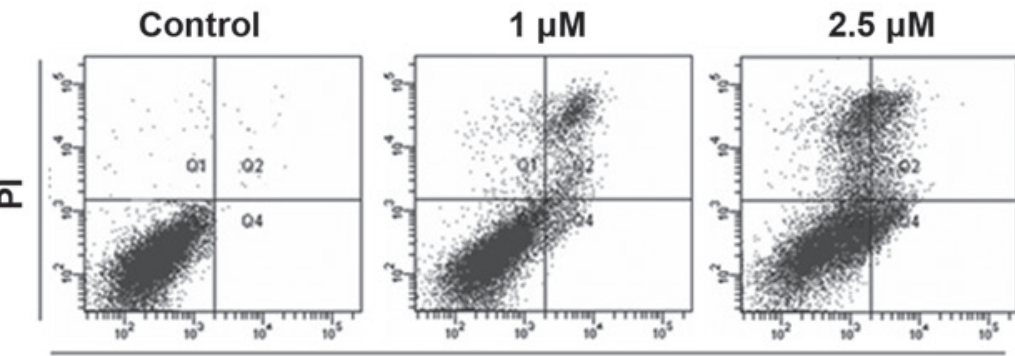

Annexin-V

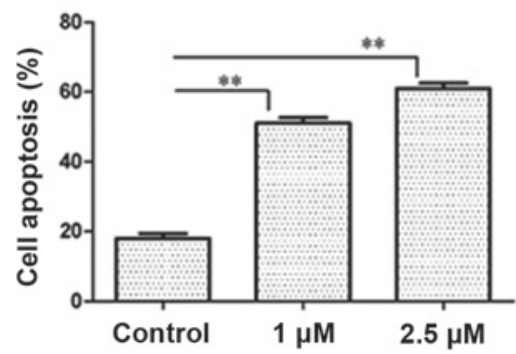

C

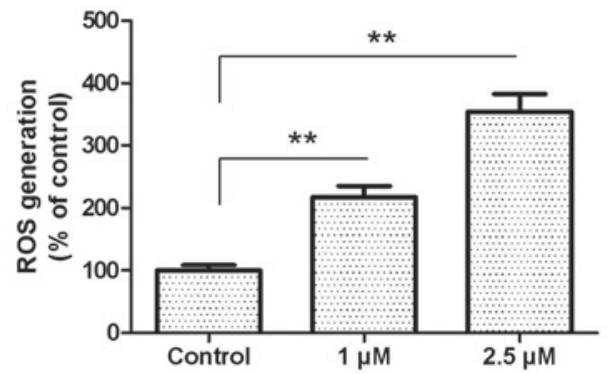

Figure 2. Evodiamine induced apoptosis, increased ROS expression and arrested the cell cycle in A549 cells. (A) Cells were treated with 1 and $2.5 \mu \mathrm{M}$ evodiamine for $24 \mathrm{~h}$. PI staining was used to analyze the cell cycle distribution. (B) Evodiamine (1 and $2.5 \mu \mathrm{M})$ exposure in A549 cells was assessed by Annexin V-fluorescein isothiocyanate and PI double staining and fluorescence-activated cell sorter analysis. (C) ROS generation in A549 cells treated with 1 and $2.5 \mu \mathrm{M}$ evodiamine was determined. ${ }^{* *} \mathrm{P}<0.01$ vs. control. PI, propidium iodide; ROS, reactive oxygen species; NAC, N-acetyl-L-cysteine.

no. sc-293111; 1:1,000); SHH (cat. no. sc-373779; 1:1,000) and GLI1 (cat. no. sc-20687; 1:1,000) (all from Santa Cruz Biotechnology, Inc., Dallas, TX, USA) at $4^{\circ} \mathrm{C}$ overnight. The membrane was washed 3 times with tris-buffered saline and Tween-20 (TBST) for 15 min each time. Horseradish peroxidase-labeled goat anti-rabbit secondary antibody (cat. no. sc-516087; 1:4,000) was added and incubated at room temperature for $1.5 \mathrm{~h}$. The membrane was washed again 3 times with TBST for 15 min per wash. Finally, enhanced chemiluminescence developing agent was used for coloration and fixation.

Reduced glutathione (GSH) assay. Tumor cells $\left(5 \times 10^{5}\right)$ in logarithmic growth phase were seeded in 6-well plates and cultured for $24 \mathrm{~h}$. PBS or 1 or $2.5 \mu \mathrm{M}$ evodiamine were separately added to the test wells and cultured for $24 \mathrm{~h}$. Reduced $\mathrm{GSH}$ in the cells was quantified using a commercial GSH determination kit (Jiancheng Institute of Biotechnology, Nanjing, China), following the manufacturer's protocol. The result was detected by spectrophotometry at $420 \mathrm{~nm}$.

Telomerase activity assay. Tumor cells $\left(5 \times 10^{5}\right)$ in logarithmic growth phase were seeded in 6-well plates and cultured for $24 \mathrm{~h}$. PBS or 1 or $2.5 \mu \mathrm{M}$ evodiamine were separately added to the test wells and cells were cultured for $24 \mathrm{~h}$. Cell pellets were washed twice with cold PBS, and the cells were then lysed with an appropriate volume of the provided lysis buffer from the protein extraction kit (Beyotime Institute of Biotechnology). After $30 \mathrm{~min}$ of incubation on ice, the suspension was centrifuged for $30 \mathrm{~min}$ at $4^{\circ} \mathrm{C}$ and $12,000 \mathrm{x} \mathrm{g}$. The supernatant $(2 \mu \mathrm{l})$ was then used to to assess the telomerase activity. The telomerase activity was determined by SYBR Green real-time PCR.

Statistical analysis. The data are presented as the mean \pm standard deviation and analyzed with SPSS 13.0 software (SPSS, Inc., Chicago, IL, USA). Data were compared with one-way analysis of variance followed by the Bonferroni test. $\mathrm{P}<0.05$ was considered to indicate a statistically significant difference.

\section{Results}

Evodiamine significantly inhibits in vitro proliferation of A549 cells. An MTS assay was used to investigate the effect of evodiamine treatment for $72 \mathrm{~h}$ on in vitro proliferation of 

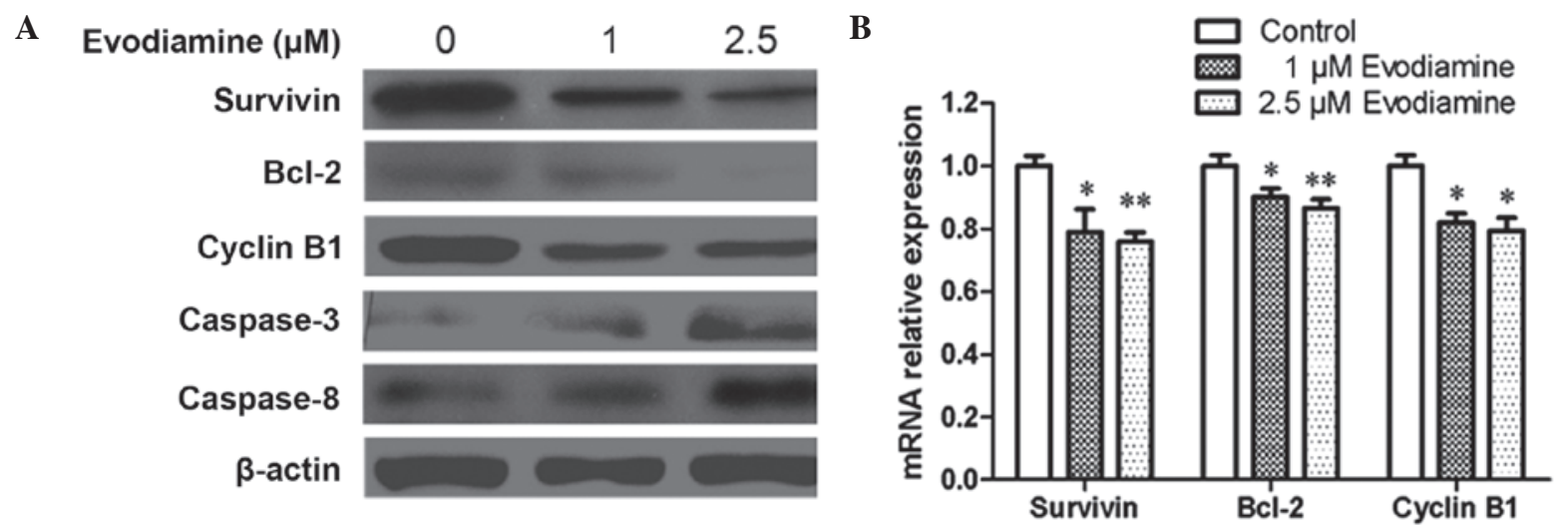

Figure 3. Evodiamine regulated proliferation-associated genes in A549 cells. (A) Immunoblotting of the proteins associated with proliferation. Immunoblot analyses were performed on the lysates of A549 cells that were incubated with 1 and $2.5 \mu \mathrm{M}$ evodiamine for $48 \mathrm{~h}$. Equal protein loading was verified by $\beta$-actin. Results were confirmed by repeated experiments. (B) A549 cells treated with 1 and $2.5 \mu \mathrm{M}$ evodiamine for $48 \mathrm{~h}$. Total cellular RNA were collected and subjected to reverse transcription-quantitative polymerase chain reaction. ${ }^{*} \mathrm{P}<0.05$ and ${ }^{* * *} \mathrm{P}<0.01$ vs. control.

A549 cells. The results indicated that evodiamine significantly inhibited the in vitro proliferation of A549 cells (Fig. 1).

Evodiamine induces apoptosis and ROS expression, and arrests the $A 549$ cell cycle. When treated with 1 and $2.5 \mu \mathrm{M}$ evodiamine, the distribution of cells in different phases of the cell cycle changed significantly compared with control, with the majority of cells arrested at the G2/M phase (Fig. 2A). Evodiamine at 1 and $2.5 \mu \mathrm{M}$ was used to determine its effect on apoptosis. Incubation with 1 and $2.5 \mu \mathrm{M}$ evodiamine for $24 \mathrm{~h}$ significantly induced apoptosis $(\mathrm{P}<0.01$; Fig. $2 \mathrm{~B})$. Following the incubation of the tumor cells with 1 and $2.5 \mu \mathrm{M}$ evodiamine for $24 \mathrm{~h}$, the ROS level was $217.3 \%$ and $354.2 \%$ compared with the control group $(\mathrm{P}<0.05$; Fig. $2 \mathrm{C})$. However, no significant difference was identified in ROS production in the NAC group (data not shown); therefore, evodiamine-induced tumor cell apoptosis may be associated with oxidative injury in these cells.

Evodiamine regulates proliferation-associated gene expression in A549 cells. To further investigate the inhibitory effect of evodiamine and its mechanism of action on tumor cell proliferation, the changes in proliferation-associated gene expression were examined. The results indicated that the protein and mRNA expression levels of survivin, Bcl-2, cyclin B1, p-Src, SHH and GLI1 proteins were downregulated following incubated with 1 and $2.5 \mu \mathrm{M}$ evodiamine for $24 \mathrm{~h}$ (Fig. 3).

Evodiamine reduces telomerase activity in A549 cells. In order to evaluate the role of evodiamine in the regulation of telomerase activity in A549 cells, the cells were cultured with $1 \mu \mathrm{M}$ evodiamine for increasing time periods. Addition of evodiamine to A549 cells substantially reduced the telomerase activity $(\mathrm{P}<0.01$; Fig. 4).

Evodiamine affects the cellular GSH content in A549 cells. GSH is important for the antioxidant defense of cells. Under oxidative stress conditions, ROS are reduced by GSH by the concomitant formation of glutathione disulfide (GSSG). The intracellular concentration of GSH for detoxifying ROS

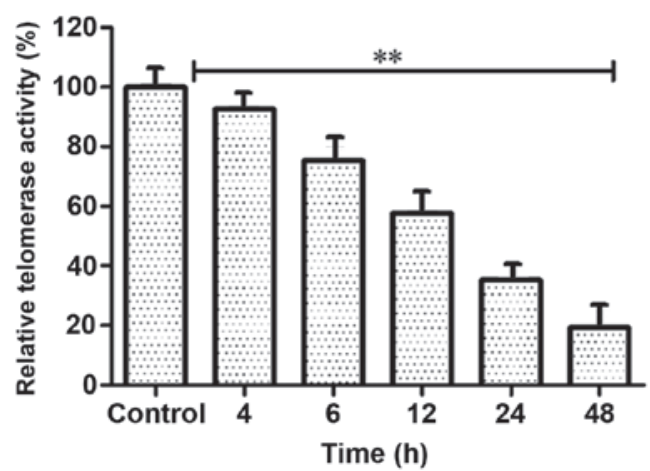

Figure 4. Evodiamine affected telomerase activity in A549 cells as determined by a telomerase activity assay. Activity of control cells was regarded to be $100 \%$. Cells were treated with evodiamine at 1 and $2.5 \mu \mathrm{M}$ for $24 \mathrm{~h}$. ${ }^{* *} \mathrm{P}<0.01$ vs. control.

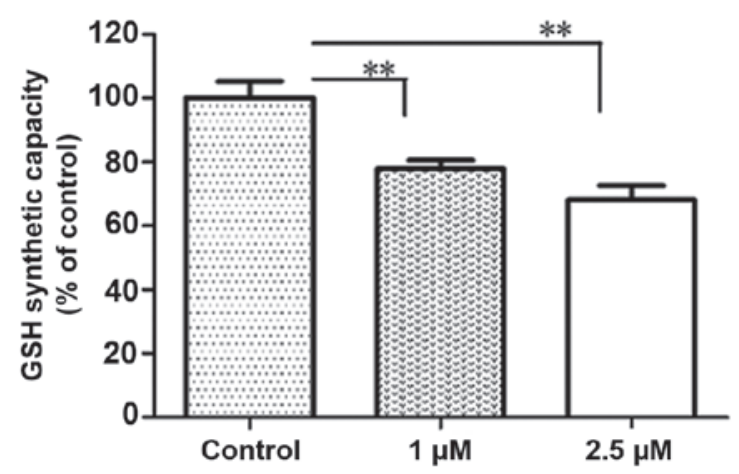

Figure 5. Evodiamine affected GSH content in the A549 cells. The cellular GSH content assessed in cells treated with 1 and $2.5 \mu \mathrm{M}$ evodiamine for $24 \mathrm{~h}$ was also analyzed. ${ }^{* *} \mathrm{P}<0.01$ vs. control. GSH, glutathione.

significantly decreased following treatment with 1 and $2.5 \mu \mathrm{M}$ evodiamine for $24 \mathrm{~h}(\mathrm{P}<0.01$; Fig. 5). No significant difference in ROS production with 1 and $2.5 \mu \mathrm{M}$ evodiamine by NAC treatment when compared with the control.

Effect of evodiamine on cell proliferation through SHH/GLII signaling in A549 cells. SHH is a member of the family of 


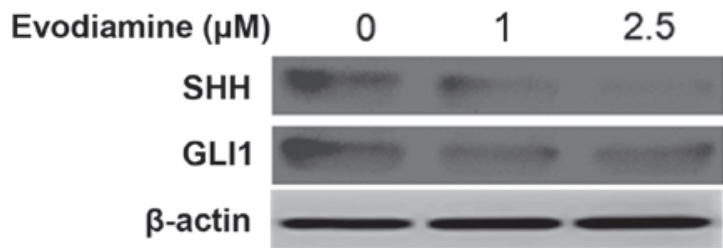

C

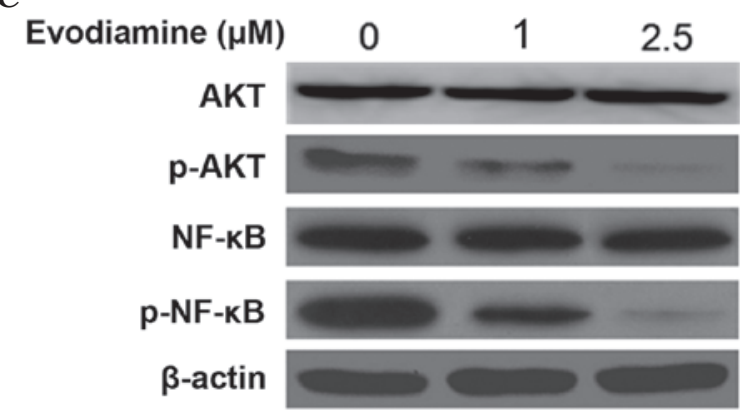

Figure 6. Evodiamine modulates SHH/GLI1 levels through inhibition of AKT/NF-кB in A549 cells. (A) Immunoblots for the proteins associated with proliferation. Immunoblot analyses were performed on the lysates of A549 cells incubated with 1 and $2.5 \mu \mathrm{M}$ evodiamine for $48 \mathrm{~h}$. Equal protein loading was verified by $\beta$-actin. (B) Reverse transcription-quantitative polymerase chain reaction analysis of mRNA expression levels of SHH and GLI1 in A549 cells. (C) Phosphorylation of key signaling proteins for the AKT/NF-kB pathway determined by western blotting. Three independent experiments were performed. ${ }^{*} \mathrm{P}<0.05$ and ${ }^{* *} \mathrm{P}<0.01$ vs. control. SHH, sonic hedgehog; GLI-1, GLI family zinc finger 1; p-, phosphorylated; NF- $\mathrm{kB}$, nuclear factor- $-\mathrm{k}$.

hedgehog proteins. It is critical for oligodendrocyte development, including induction, survival, proliferation and migration of oligodendrocytes and control of axon growth $(10,11)$. SHH binds to the transmembrane receptor protein, patched, to activate the transmembrane receptor, smoothened, and induces a complex series of intracellular reactions that target the GLI family of transcription factors. GLI1 is the principal effector of SHH signaling in neural progenitor cells $(12,13)$. To assess the effect of evodiamine on the SHH/GLI1 signaling pathway, A549 cells were treated with 1 and $2.5 \mu \mathrm{M}$ evodiamine. The protein and mRNA expression levels of GLI1 and SHH were reduced following evodiamine treatment (Fig. 6A and B). These findings suggest that evodiamine decreases the cellular levels of SHH and GLI1.

Evodiamine modulates $S H H / G L I 1$ levels through inhibition of the AKT/NF- $\kappa B$ pathway. Recent studies have demonstrated that phosphoinositide 3-kinase (PI3K)/AKT induction of cell survival signals is mediated, in part, through the activation of the NF- $\kappa \mathrm{B}$ transcription factor (14-16). NF- $\kappa \mathrm{B}$ is important for tumorigenesis and tumor progression. It is associated with various signal transduction pathways and transcription activation events that mediate cell proliferation, cell migration and angiogenesis. Aberrant or constitutively activated NF- $\mathrm{KB}$ has been detected in human cancer $(17,18)$. To investigate the contribution of the AKT/NF- $\mathrm{BB}$ signaling pathway to the inhibition of the SHH/GLI1 pathway, AKT and NF- $\kappa \mathrm{B}$ phosphorylation was analyzed by immunoblotting. AKT and NF- $\kappa B$ phosphorylation levels were decreased following treatment with evodiamine (Fig. 6C). These results suggested that evodiamine inhibited cell proliferation via inhibition of SHH/GLI1/AKT/NF-кB signaling in A549 cells.

\section{Discussion}

Lung cancer is a common type of human malignancy, and its incidence in Asia is increasing. There is a low 5-year survival rate despite routine surgery and chemotherapy, which is due to distant metastases (19). Growing evidence highlights natural products with antitumor activity (20). It was reported that $>20$ alkaloids have been extracted and separated from E. rutaecarpa, and were shown to be the main active components $(21,22)$. Futhermore, evodiamine, an indole alkaloid, is considered to be the main active ingredient in the total alkaloids. The experimental study on pharmacological activity determined that evodiamine had clear antitumor activity $(23,24)$; however, the effect of evodiamine on lung cancer has not been adequately determined, to the best of our knowledge.

The present study demonstrated that evodiamine was able to significantly inhibit the in vitro proliferation of A549 cells. Under 1 and $2.5 \mu \mathrm{M}$ concentrations, evodiamine significantly enhanced apoptosis. At 1 and $2.5 \mu \mathrm{M}$ concentrations, evodiamine arrested the tumor cell cycle at the G2/M phase; therefore, the 1 and $2.5 \mu \mathrm{M}$ concentration was used in the remaining experiments to prevent interference of tumor cell death. The molecular mechanism of evodiamine-induced inhibition of tumors was further investigated. It was determined that evodiamine induced tumor cells to produce ROS capable of initiating apoptosis of tumor cells. GSH is important for the antioxidant defense of cells (25). The intracellular 
concentration of GSH reflects a dynamic balance between the synthesis and consumption of GSH within the cell and loss through efflux. Under oxidative stress conditions, ROS are reduced by GSH with concomitant formation of the GSSG (26). The present study determined that the GSH level was also reduced following evodiamine treatment. Therefore, it is possible that evodiamine increased ROS levels via inhibition of GSH activity.

Previous studies have indicated that evodiamine may stimulate the production of ROS to induce apoptosis by causing mitochondrial damage $(27,28)$. The present study found that following treatment with evodiamine, the anti-apoptotic genes Survivin and Bcl-2 in the mitochondria-associated apoptosis pathway were significantly downregulated, while the downstream caspase- 3 and caspase- 8 activity was significantly upregulated, indicating that the mitochondrial pathway is important for evodiamine-induced apoptosis. In addition, corresponding changes in the expression of cell cycle regulatory gene cyclin B1 was also observed.

Telomerase is a ribonucleoprotein complex, which is active in the majority tumors (29) and is important in tumor proliferation and metastasis. Previous studies have demonstrated, that telomerase activity is required for the malignant properties of cancer cells and may be a good target for the development of anticancer therapeutic agents (30,31). Additionally, mortalin overexpression cooperates with telomerase to extend the in vitro lifespan of normal human fibroblasts (32). When this is considered with the present data, it is possible that nuclear mortalin interacts with telomerase and activates its function contributing to proliferation and the malignant characteristics of cancer cells. Telomerase may be associated with the inhibition of apoptotic signaling and may be involved in the regulated process of apoptosis, which to the best of our knowledge, has not been fully elucidated. The present study determined that evodiamine may inhibit telomerase activity, suggesting that the downregulation of $\mathrm{Bcl}-2$ and telomerase may be important for evodiamine-induced apoptosis.

The mechanism of evodiamine-induced inhibition of tumors was investigated using signal transduction molecules. The SHH/GLI1 signaling pathway is an important signal transduction pathway, which is abnormally activated in lung cancer cells and is important for oncogenesis and tumor development. It primarily consists of the signaling molecule $\mathrm{SHH}$ and the downstream transcription factor GLI1, hence it is termed the SHH/GLI1 signaling pathway. Additionally, it is involved in the growth, invasion, metastasis, epithelial-mesenchymal transition, apoptosis, angiogenesis and multiple related aspects of tumor cells. The present study detected the changes in the SHH/GLI1 signaling pathway when A549 cell proliferation was inhibited by evodiamine.

The activation of the PI3K/AKT signaling pathway is involved in cell proliferation, survival, apoptosis and malignant transformation, by regulating $\mathrm{NF}-\kappa \mathrm{B}$ activation in several cell lines (33). The $\mathrm{NF}-\kappa \mathrm{B}$ family of transcription factors controls the expression of genes involved in immune and inflammatory responses, cell proliferation, oncogenesis, angiogenesis and Bcl-2 family members (34). NF- $\kappa \mathrm{B}$ is important for the resistance of cancer cells to anticancer therapies by protecting them from apoptosis (35). The present study determined that evodiamine inhibited the activation of AKT and $\mathrm{NF}-\kappa \mathrm{B}$.
In addition, $\mathrm{NF}-\kappa \mathrm{B}$ has been shown to contribute to $\mathrm{SHH}$ signaling activation through $\mathrm{SHH}$ ligand induction in pancreatic cells (36). The inhibitory effect of evodiamine on $\mathrm{SHH}$ and GLI1 signaling by NF- $\mathrm{BB}$ observed in the present study suggested that $\mathrm{NF}-\kappa \mathrm{B}$ stimulates $\mathrm{SHH}$ signaling. In conclusion, these results suggest that evodiamine may be a potential anticancer agent for the treatment of lung cancer.

\section{References}

1. Wang N, Liang H, Zhou Y, Wang C, Zhang S, Pan Y, Wang Y, Yan X, Zhang J, Zhang CY, et al: miR-203 suppresses the proliferation and migration and promotes the apoptosis of lung cancer cells by targeting SRC. PLoS One 9: e105570, 2014.

2. Zhao L, Li C, Zhang Y, Wen Q and Ren D: Phytochemical and biological activities of an anticancer plant medicine: Brucea javanica. Anticancer Agents Med Chem 14: 440-458, 2014.

3. De Marchi T, Foekens JA, Umar A and Martens JW: Endocrine therapy resistance in estrogen receptor (ER)-positive breast cancer. Drug Discov Today 7: 1181-1188, 2016.

4. Camidge DR: Targeted therapy vs chemotherapy: Which has had more impact on survival in lung cancer? Does targeted therapy make patients live longer? Hard to prove, but impossible to ignore. Clin Adv Hematol Oncol 12: 763-766, 2014.

5. Wahl O, Oswald M, Tretzel L, Herres E, Arend J and Efferth T: Inhibition of tumor angiogenesis by antibodies, synthetic small molecules and natural products. Curr Med Chem 18: 3136-3155, 2011.

6. Ruden M and Puri N: Novel anticancer therapeutics targeting telomerase. Cancer Treat Rev 39: 444-456, 2013.

7. Liao CH, Pan SL, Guh JH, Chang YL, Pai HC, Lin CH and Teng CM: Antitumor mechanism of evodiamine, a constituent from Chinese herb Evodiae fructus, in human multiple-drug resistant breast cancer NCI/ADR-RES cells in vitro and in vivo. Carcinogenesis 26: 968-975, 2005.

8. Chen MC, Yu CH, Wang SW, Pu HF, Kan SF, Lin LC, Chi CW, Ho LL, Lee CH and Wang PS: Anti-proliferative effects of evodiamine on human thyroid cancer cell line ARO. J Cell Biochem 110: 1495-1503, 2010.

9. Livak KJ and Schmittgen TD: Analysis of relative gene expression data using real-time quantitative PCR and the 2(-Delta Delta C(T)) method. Methods 25: 402-408, 2001.

10. Merchán P, Bribián A, Sánchez-Camacho C, Lezameta $M$ Bovolenta $\mathrm{P}$ and de Castro F: Sonic hedgehog promotes the migration and proliferation of optic nerve oligodendrocyte precursors. Mol Cell Neurosci 36: 355-368, 2007.

11. Seifert T, Bauer J, Weissert R, Fazekas F and Storch MK: Differential expression of sonic hedgehog immunoreactivity during lesion evolution in autoimmune encephalomyelitis. J Neuropathol Exp Neurol 64: 404-411, 2005.

12. Wetmore C: Sonic hedgehog in normal and neoplastic proliferation: Insight gained from human tumors and animal models. Curr Opin Genet Dev 13: 34-42, 2003.

13. Gomes DC, Leal LF, Mermejo LM, Scrideli CA, Martinelli CE Jr, Fragoso MC, Latronico AC, Tone LG, Tucci S, Yunes JA, et al: Sonic hedgehog signaling is active in human adrenal cortex development and deregulated in adrenocortical tumors. J Clin Endocrinol Metab 99: E1209-E1216, 2014.

14. Chen KC, Chen CY, Lin CR, Yang TY, Chen TH, Wu LC and Wu CC: Luteolin attenuates TGF- $\beta 1$-induced epithelial-mesenchymal transition of lung cancer cells by interfering in the PI3K/Akt-NF-kB-Snail pathway. Life Sci 93: 924-933, 2013.

15. Peng Y, Huang S, Wu Y, Cheng B, Nie X, Liu H, Ma K, Zhou J, Gao D, Feng C, et al: Platelet rich plasma clot releasate preconditioning induced PI3K/AKT/NFKB signaling enhances survival and regenerative function of rat bone marrow mesenchymal stem cells in hostile microenvironments. Stem Cells Dev 22: 3236-3251, 2013.

16. Rasul A, Ding C, Li X, Khan M, Yi F, Ali M and Ma T: Dracorhodin perchlorate inhibits PI3K/Akt and NF- $\mathrm{BB}$ activation, up-regulates the expression of $\mathrm{p} 53$, and enhances apoptosis. Apoptosis 17: 1104-1119, 2012.

17. Yang J and Richmond AJ: Monitoring NF-kappaB mediated chemokine transcription in tumorigenesis. Methods Enzymol 460: 347-355, 2009. 
18. Li L, Yue GG, Pu JX, Sun HD, Fung KP, Leung PC, Han QB, Lau CB and Leung PS: Eriocalyxin B-induced apoptosis in pancreatic adenocarcinoma cells through thiol-containing antioxidant systems and downstream signalling pathways. Curr Mol Med 14: 673-689, 2014.

19. Qi Z, Yang DY and Cao J: Increased micro-RNA 17, 21, and 192 gene expressions improve early diagnosis in non-small cell lung cancer. Med Oncol 31: 195, 2014.

20. Robles-Fernández I, Rodríguez-Serrano F, Álvarez PJ, Ortiz R, Rama AR, Prados J, Melguizo C, Álvarez-Manzaneda E and Aránega A: Antitumor properties of natural compounds and related molecules. Recent Pat Anticancer Drug Discov 8: 203-215, 2013.

21. Wang XX, Zan K, Shi SP, Zeng KW, Jiang Y, Guan Y, Xiao CL, Gao HY, Wu LJ and Tu PF: Quinolone alkaloids with antibacteria and cytotoxic activities from the fruits of Evodia rutaecarpa. Fitoterapia 89: 1-7, 2013.

22. Ko JS, Rho MC, Chung MY, Song HY, Kang JS, Kim K, Lee HS and Kim YK: Quinolone alkaloids, diacylglycerol acyltransferase inhibitors from the fruits of Evodia rutaecarpa. Planta Med 68: 1131-1133, 2002

23. Liu AJ, Wang SH, Chen KC, Kuei HP, Shih YL, Hou SY, Chiu WT, Hsiao SH and Shih CM: Evodiamine, a plant alkaloid, induces calcium/JNK-mediated autophagy and calcium/mitochondria-mediated apoptosis in human glioblastoma cells. Chem Biol Interact 205: 20-28, 2013.

24. Pan X, Hartley JM, Hartley JA, White KN, Wang Z and Bligh SW: Evodiamine, a dual catalytic inhibitor of type I and II topoisomerases, exhibits enhanced inhibition against camptothecin resistant cells. Phytomedicine 19: 618-624, 2012.

25. Sharma T, Airao V, Panara N, Vaishnav D, Ranpariya V, Sheth $\mathrm{N}$ and Parmar S: Solasodine protects rat brain against ischemia/reperfusion injury through its antioxidant activity. Eur J Pharmacol 725: 40-46, 2014

26. Tobwala S, Fan W, Hines CJ, Folk WR and Ercal N: Antioxidant potential of Sutherlandia frutescens and its protective effects against oxidative stress in various cell cultures. BMC Complement Altern Med 14: 271, 2014.
27. Xue S, Chen YX, Qin SK, Yang AZ, Wang L, Xu HJ and Geng HY: Raltitrexed induces mitochondrial-mediated apoptosis in SGC7901 human gastric cancer cells. Mol Med Rep 10: 1927-1934, 2014

28. Ma L, Li X, Wang Y, Zheng W and Chen T: Cu(II) inhibits hIAPP fibrillation and promotes hIAPP-induced beta cell apoptosis through induction of ROS-mediated mitochondrial dysfunction. J Inorg Biochem 140: 143-152, 2014.

29. Murnane JP: Telomere dysfunction and chromosome instability. Mutat Res 730: 28-36, 2012.

30. Saretzki G: Extra-telomeric functions of human telomerase: cancer, mitochondria and oxidative stress. Curr Pharm Des 41: 6386-6403, 2014

31. Rasul A, Yu B, Zhong L, Khan M, Yang H and Ma T: Cytotoxic effect of evodiamine in SGC-7901 human gastric adenocarcinoma cells via simultaneous induction of apoptosis and autophagy. Oncol Rep 27: 1481-1487, 2012.

32. Kaul SC, Yaguchi T, Taira K, Reddel RR and Wadhwa R: Overexpressed mortalin (mot-2)/mthsp70/GRP75 and hTERT cooperate to extend the in vitro lifespan of human fibroblasts. Exp Cell Res 286: 96-101, 2003.

33. Altomare DA and Testa JR: Perturbations of the AKT signaling pathway in human cancer. Oncogene 24: 7455-7464, 2005.

34. Shao N, Lu Z, Zhang Y, Wang M, Li W, Hu Z, Wang S and Lin Y Interleukin-8 upregulates integrin $\beta 3$ expression and promotes estrogen receptor-negative breast cancer cell invasion by activating the PI3K/Akt/NF-кB pathway. Cancer Lett 364: 165-172, 2015.

35. Liu Y, Zhu P, Wang Y, Wei Z, Tao L, Zhu Z, Sheng X, Wang S, Ruan J, Liu Z, et al: Antimetastatic therapies of the Polysulfide Diallyl Trisulfide against triple-negative breast cancer (TNBC) via suppressing MMP2/9 by blocking NF- $\kappa \mathrm{B}$ and ERK/MAPK signaling pathways. PLoS One 10: e0123781, 2015.

36. Cardenas-Rodriguez $M$ and Badano JL: Ciliary biology: Understanding the cellular and genetic basis of human ciliopathies. Am J Med Genet C Semin Med Genet 151C: 263-280, 2009. 